OPEN ACCESS

Edited by:

Bruno Bonaz,

Centre Hospitalier Universitaire de

Grenoble, France

Reviewed by:

Gianluca Matteoli,

KU Leuven, Belgium

Keisa Williams Mathis,

University of North Texas Health

Science Center, United States

*Correspondence:

Xia Liu

Ixflying@aliyun.com

Yang Sun

dawnysun@126.com

${ }^{\dagger}$ These authors have contributed equally to this work

Specialty section: This article was submitted to Inflammation,

a section of the journal

Frontiers in Immunology

Received: 08 September 2020 Accepted: 29 December 2020 Published: 08 February 2021

Citation:

Qin Z, Xiang K, Su D-F, Sun Y and Liu X (2021) Activation of the Cholinergic Anti-Inflammatory Pathway as a Novel Therapeutic Strategy for COVID-19.

Front. Immunol. 11:595342. doi: 10.3389/fimmu.2020.595342

\section{Activation of the Cholinergic Anti- Inflammatory Pathway as a Novel Therapeutic Strategy for COVID-19}

\author{
Zhen Qin ${ }^{1,2 \dagger}$, Kefa Xiang ${ }^{1 \dagger}$, Ding-Feng Su ${ }^{1}$, Yang Sun ${ }^{1 *}$ and Xia Liu ${ }^{1 *}$ \\ ${ }_{1}^{1}$ Department of Clinical Pharmacy, School of Pharmacy, Second Military Medical University, Shanghai, China, \\ 2 Key Laboratory of Molecular Pharmacology and Drug Evaluation (Yantai University), Ministry of Education, Yantai University, \\ Yantai, China
}

The outbreak of coronavirus disease 2019 (COVID-19) underlined the urgent need for alleviating cytokine storm. We propose here that activating the cholinergic antiinflammatory pathway (CAP) is a potential therapeutic strategy. However, there is currently no approved drugs targeting the regulatory pathway. It is evident that nicotine, anisodamine and some herb medicine, activate the CAP and exert anti-inflammation action in vitro and in vivo. As the vagus nerve affects both inflammation and specific immune response, we propose that vagus nerve stimulation by invasive or non-invasive devices and acupuncture at ST36, PC6, or GV20, are also feasible approaches to activate the CAP and control COVID-19. It is worth to investigate the efficacy and safety of the strategy in patients with COVID-19.

Keywords: coronavirus disease 2019, cytokine storm, cholinergic anti-inflammatory pathway, therapeutic strategy, vagus nerve stimulation

\section{INTRODUCTION}

A novel human coronavirus, severe acute respiratory syndrome coronavirus 2 (SARS-CoV-2), has been rapidly spreading across the world. SARS-CoV-2 is a single-strand, positive-sense, RNA virus and shares $\sim 79 \%$ similarity of the genome sequence with human severe acute respiratory syndrome coronavirus (SARS-CoV) $(1,2)$. WHO has declared this coronavirus disease 2019 (COVID-19) a pandemic on 11 March, 2020. By Nov. 26, 2020, there have been 60,074,174 confirmed cases of COVID-19 globally, including 1,416,292 deaths (3). Most people infected with the SARS-CoV-2 will experience mild to moderate respiratory illness such as fever, cough, vomiting, diarrhea, and other symptoms, which do not need special treatment. A small part of patients, especially those with underlying medical problems such as obesity, diabetes, cardiovascular diseases, chronic respiratory diseases and cancer, are more likely to develop serious pneumonia, acute respiratory distress syndrome (ARDS), or multiple organ failure, resulting in considerable morbidity and mortality (4-6).

To date, no drugs have proven effective in reducing mortality, although some showed benefits in improving symptoms and shortening course. The Food and Drug Administration (FDA) has issued an emergency-use authorization (EUA) of remdesivir as the first drug approved to treat COVID-19 on Oct. 22, 2020 (7). However, due to lacking of evidence in the improvement of survival and other outcomes, WHO recommends against the use of remdesivir in COVID-19 




GRAPHICAL ABSTRACT | Proposed approaches of activating cholinergic anti-inflammatory pathway. (A) Pharmacological activation: Nicotine, anisodamine, and some Chinese herbs could direct or indirectly exert pharmacological activation of $\alpha 7 n A C h R$. (B) Physical activation: vagus nerve stimulation, such as invasive or noninvasive VNS device shown in Figure 1, increases the activity of cholinergic anti-inflammatory pathway. (C) Physical activation: some acupuncture points increase the activity of cholinergic anti-inflammatory pathway by activating the afferent vagal. Zu San Li (ST36) is located four finger widths down from the bottom of knee cap, along the outer boundary of shin bone. Nei Guan (PC6) is located three finger breadths below the wrist on the inner forearm in between the two tendons. Feishu (BL13) is on the back, $5 \mathrm{~cm}$ lateral to the lower border of the spinous process of the 3rd thoracic vertebra. Bainui (GV20) is on the center of the top of the head where the line connecting the high points of ears crosses the body midline.

patients (8). At present, there is also not yet an authorized vaccine to prevent COVID-19 in the United States (Updated Nov. 20, 2020) (9). Finding new effective COVID-19 treatments is still critical.

\section{CYTOKINE STORM: LETHAL FACTOR AND THERAPEUTIC DILEMMA}

Accumulating evidence showed clinical and laboratory features of a cytokine storm syndrome in patients with severe COVID-19 (10). Cytokine storms are a common complication of infectious diseases, not only in COVID-19 but also in flu, SARS and MERS. Essentially, it is the overreaction of immune system to infection. For SARS-CoV-2, it enters the lungs, and its S protein specifically recognizes the host angiotensin-converting enzyme 2 (ACE2) receptor in alveolar epithelial type 2 cells. Upon binding, host serine protease TMPRSS2 cleaves the $S$ protein and results in the fusion of the viral and cellular membranes, then SARS-CoV-2 enters into host cells (11). Consequently, the host initiates immune response and local inflammation to remove the virus.

\footnotetext{
Abbreviations: ACh, acetycholine; AChE, acetyl cholinesterase enzyme; CAP, cholinergic anti-inflammatory pathway; ChAT, choline acetyltransferase; COVID19, coronavirus disease 2019; DIC, disseminated intravascular coagulation; DKT, Daikenchuto; HLJDD, Huang-Lian-Jie-Du decoction; JTW, Jiao-Tai-Wan; QFPDD, Qing-Fei-Pai-Du decoction; SARS-CoV-2, severe acute respiratory syndrome coronavirus 2; TCM, traditional Chinese medicine; VNS, vagus nerve stimulation; $\alpha 7 \mathrm{nAChRs,} \alpha 7$ subunit-containing nicotinic receptors.
}

This viral infection-mediated local inflammatory response results in direct injury to the lung tissue, which is one of the proposed mechanisms behind the pulmonary manifestations of COVID-19 (11). However, in some patients, the release of cytokines is excessive or uncontrolled, leading to multiple organ failure, and a lethal consequence to the hosts (12). Before the effective vaccines or anti-viral drugs for COVID-19 are developed, anti-inflammation treatments are the urgent needs to calm cytokine storms and save lives $(13,14)$.

The existing, approved drugs with inflammation suppression are proposed as therapeutic options. Corticosteroids are getting special attention. However, their effects are still debatable, because they not only suppress lung inflammation but also impair the immune system's ability to fight viruses. Clinical data did not support survival benefit from corticosteroids use in patients with coronavirus infection including SARS-CoV-2, even there are several possible harms (including delayed viral clearance) (15). Several anti-cancer drugs might be beneficial in states of overwhelming immune response like septic shock. Once again, due to immunosuppression, the present evidence is not enough to give any recommendations for routine clinical use (16). The effect of NSAIDs in COVID-19 patients is unknown (17). It can speculate that NSAIDs may have a beneficial effect in relieving symptoms caused by prostaglandins, but they do not directly affect the production of pro-inflammatory cytokines. A multi-source analysis in 2019 conducted by the CRPVs showed that NSAIDs administration increased the risk of bacterial infections (in particular pulmonary infections). At present, symptomatic treatment with NSAIDs is not recommended in 
patients with suspected COVID-19 cases (18-20). Some inhibitors or antibodies, based on their anti-inflammatory properties, are the potential agents for COVID-19 infection (e.g., JAK1/2 inhibitor baricitinib, IL-6 receptor blockade tocilizumab). Previous studies did not show a positive effect of these treatments in patients with cytokine storm of sepsis (21). Recently, John H. Stone et al. also reported that tocilizumab was not effective for preventing intubation or death in moderately ill hospitalized patients with COVID-19, suggesting that blocking single pro-inflammatory factor might not be sufficient to control cytokine storm (22). At present, the clinical trials of anti-IL-6 or anti-TNF therapy for COVID-19 are under the stage of being recommended or approved (23-25).

\section{ACTIVATING CHOLINERGIC ANTI- INFLAMMATORY PATHWAY (CAP): A NOVEL ANTI-INFLAMMATION STRATEGY FOR COVID-19 INFECTION}

Due to therapeutic dilemma of current drugs, more antiinflammation approaches are needed. The CAP represents a neural mechanism of inflammation inhibition, first identified by Tracey KJ in 2000 (26). They found parasympathetic nervous system activity influences circulating TNF amounts and the shock response to endotoxaemia, which they call the 'cholinergic antiinflammatory pathway' (26). The finding of CAP attracts considerable attention during the past 20 years and are well clarified now. In the presence of peripheral inflammation, afferent signals of vagal nerve are fired, notify the CNS and in turn activate an opposing efferent vagal nerve. The efferent vagus nerve then activates the splenic nerve to release its neurotransmitters including norepinephrine in the spleen. Subsequently, norepinephrine activates choline acetyltransferase-expressing $\mathrm{T}$ cells possibly via adrenergic receptors (AR), and promotes the production and release of T cell-derived acetylcholine (ACh). The ACh then interacts with $\alpha 7$ subunit-containing nicotinic receptor $(\alpha 7 \mathrm{nAChR})$ on macrophages and other immune cells, inhibits the release of pro-inflammatory cytokines and protects the body against damage. The efferent arm of this 'inflammatory reflex' is the CAP (27-29).

The integrity of the inflammatory reflex is critically dependent on expression of the $\alpha 7 \mathrm{nAChR}(27,30)$. In addition to immune cells, $\alpha 7 \mathrm{nAChR}$ is also wide-spread expressed in other different cells (Figure 1), including neurons and glial cells (31-33). In endotoxemia, the stimulation of vagus nerve attenuated systemic TNF levels in animals with $\alpha 7 \mathrm{nAChR}$ deficiency in the nervous system, but failed in animals with an $\alpha 7 \mathrm{nAChR}$ deficient immune system (30), identifying the $\alpha 7 n A C h R$ expressed on macrophages and other immune cells as a main mediator of CAP output (28). Intracellular mechanisms are mainly involved in the suppression of NF- $\kappa \mathrm{B}$ nuclear translocation, activation of a JAK2/STAT3 cascade, and inhibition of inflammasome activation triggered by the activation of $\alpha 7 \mathrm{nAChR}$ on mitochondria, resulting in the inhibition of TNF, IL-1 $\beta$, and other proinflammatory cytokines (34-37).
The regulation manner that neural inhibition in inflammation is faster, more effective and localized when compared to humoral ones. More importantly, it can simultaneously inhibit multiple proinflammatory cytokines, such as TNF, IL-1 $\beta$, TNF- $\alpha$, etc. Stimulation of the vagus nerve or activation of $\alpha 7 \mathrm{nAChR}$ has been effective in attenuating the production of the proinflammatory cytokines and improving the survival of animals in various inflammatory diseases, especially sepsis. Recently, activating the CAP has also been suggested a therapeutic strategy for respiratory diseases (38). Therefore, this pathway is likely to be a hopeful therapeutic intervention in COVID-19 infection.

\section{RECOMMENDED APPROACHES THAT ACTIVATE CAP IN COVID-19 INFECTION}

\section{Pharmacological Activation Nicotine}

To date, no drugs of $\alpha 7 \mathrm{nAChR}$ agonist have been approved yet. Nicotine is a nonspecific $\alpha 7 \mathrm{nAChR}$ agonist. Many studies including ours have shown the protective role of nicotine in inhibiting the production of inflammatory cytokines and improving survival in experimental sepsis through the CAP (39-41). Nicotine-releasing enemas, gums, and patches have been used to treat ulcerative colitis in clinical trials (42-45). Therefore, nicotine might serve as a feasible drug in COVID-19 infection by activating the neuro-immune regulatory pathway.

Interestingly, a study from China Medical Treatment Expert Group reported that, of the 1,085 COVID-19 patients, $85.4 \%$ were non-smokers, while only $12.6 \%$ were smokers, and $1.9 \%$ were former smokers (46). Another study from a major Paris hospital found that few who had contracted the virus were regular smokers compared to the general population. They suggested a substance, possibly nicotine in tobacco, may prevent those smokers from catching COVID-19. Although other studies showed that smoking is, or not, associated with the prevalence or severity of COVID-19 (47, 48), French researchers are planning to examine whether nicotine patches could help prevent or lessen the effects of coronavirus (49).

However, WHO recently urged researchers, scientists and the media to be cautious about amplifying unproven claims that tobacco or nicotine could reduce the risk of COVID-19 (49). We must realize there exists an essential difference in pathological process between smokers and non-smokers with COVID-19 infection. Long-term smoking has harmed respiratory system, brought a high risk of cardiovascular diseases, cancer, diabetes, etc. When people are under these existing smoking-related disease conditions, it is difficult to distinguish the true role of nicotine. Furthermore, nicotine is different from tobacoo which contains a lot of other harmful ingredients. The detrimental effect of nicotine in different organ systems are debatable. For example, the harmful effects of smoking on the kidney is rather abundant, but the data assessing the singular effects of nicotine on the kidney are sparse (50). Conversely, nicotine is reported to protect kidney from renal ischemia/reperfusion injury through the CAP (51). In most of the tobacco-related diseases, nicotine is not regarded as a direct cause 


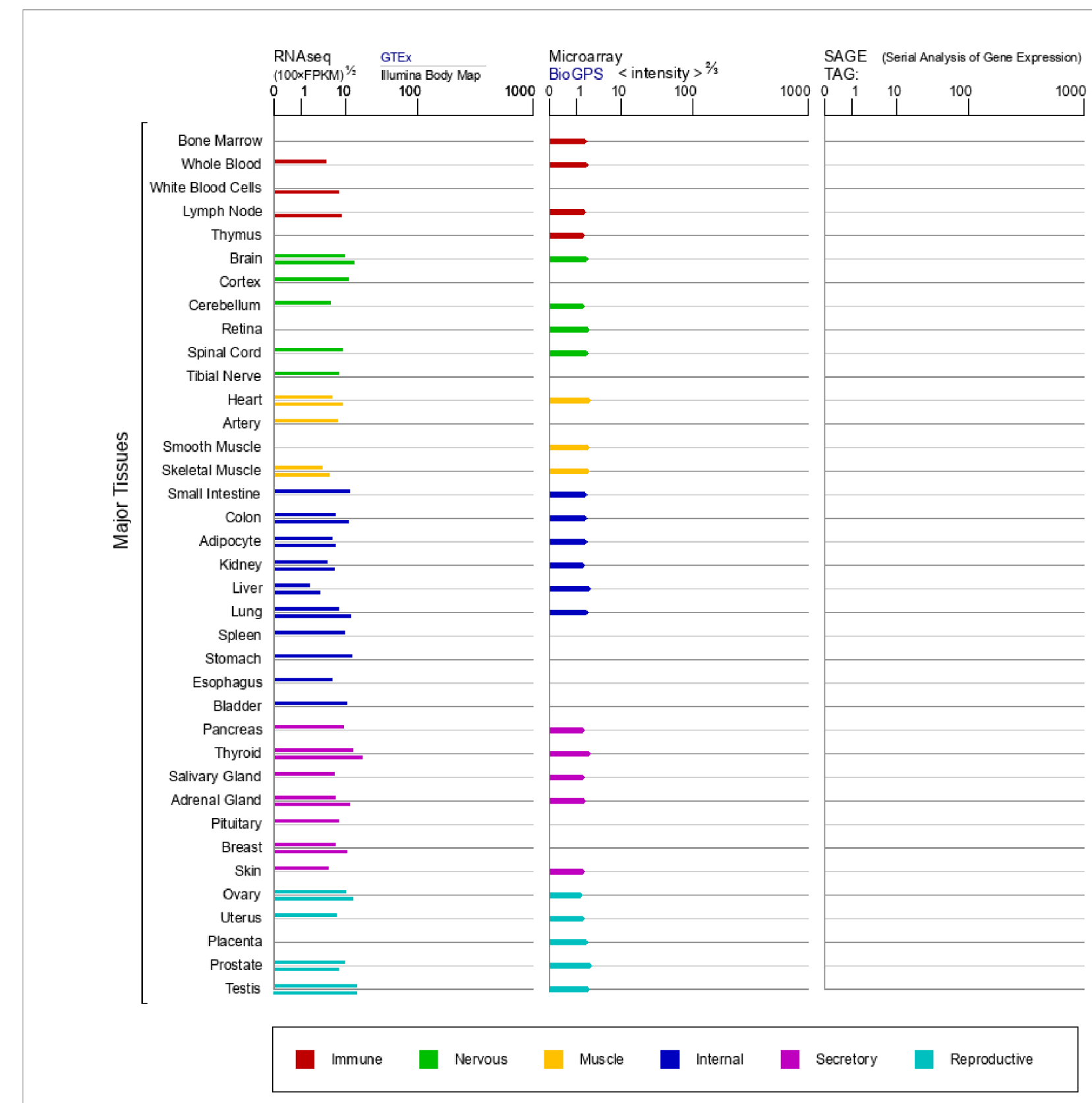

FIGURE 1 | mRNA expression in normal human tissues from GTEx, Illumina, BioGPS, and SAGE for CHRNA7 Gene (https://www.genecards.org/cgi-bin/carddisp. pl?gene=CHRNA7\&keywords $=7 \mathrm{nAChR})$.

(52). Therefore, considering the emergent need is to control cytokine storm and save lives, nicotine could at least be tried in non-smoker COVID-19 patients under the careful monitoring in the function of important organs.

\section{Anisodamine}

Anisodamine, an active ingredient of Chinese herbal extracts, is a natural atropine derivative that has been isolated, synthesized and characterized in China. Like atropine and scopolamine, it is generally considered as a non-specific muscarinic cholinergic antagonist. Since 1965, anisodamine has been widely used clinically in China for the improvement of blood flow in circulatory disorders such as septic shock and disseminated intravascular coagulation (DIC). It could sharply reduce the mortality rate of various sepsis in clinic, such as fulminant epidemic meningitis, toxic bacillary dysentery, lobar pneumonia, etc. $(53,54)$.

Many mechanisms for the anti-shock action of anisodamine were proposed. Ruan et al. found anti-shock effect of anisodamine might be related to its anti-inflammation action (55). It can counteract LPS-induced endothelial cell activation by inhibiting the NF- $\kappa \mathrm{B}$ pathway, which is a key molecule regulating the 
synthesis of pro-inflammatory cytokines. Now, series of studies suggested that its anti-inflammatory effect is mediated by indirectly activating the CAP. Li Q et al. found that the antiinflammation and anti-shock role of anisodamine was significantly attenuated in LPS-treated IL-10-/- mice when compared to wide type mice. Further studies found anisodamine increased the expression of spleen $\alpha 7 \mathrm{nAChR}$ in IL-10+/+ mice, but lose this role in IL-10-/- mice, indicating that anisodamine acts through upregulating $\alpha 7 \mathrm{nAChR}$ synergistically with endogenous IL-10 (56). Furthermore, Liu C et al. found the protective role of anisodamine in shock and inflammation was disappeared in vagotomized, $\alpha 7 \mathrm{nAChR}$-deficient, or $\alpha 7 \mathrm{nAChR}$ antagonisttreated septic mice, suggesting the involvement of the CAP. They speculate that anisodamine might block muscarinic receptor and reroute more $\mathrm{ACh}$ to bind to $\alpha 7 \mathrm{nAChR}$, therefore increasing ACh-mediated activation of $\alpha 7 \mathrm{nAChR}(57,58)$.

As an approved drug and indirect agonist of $\alpha 7 \mathrm{nAChR}$, anisodamine might be a feasible treatment for cytokine storm in COVID-19 infection. In addition to controlling inflammation, it might also provide additional advantages in COVID-19 patients. 1) COVID-19 and sticky phlegm in the lung: It was found a lot of sticky phlegm in the bronchioli and alveoli in COVID-19 death autopsy in China, which might be one of important lethal cause (59). According to the textbook of Pharmacology for medical students in China, anisodamine could antagonize $\mathrm{M}$ acetylcholine receptor, which will relieve smooth muscle spasm, inhibit gland secretion, dilate the bronchia and finally improve the function of pulmonary ventilation (60). 2) COVID-19 and abnormal coagulation: Studies have revealed that $71.4 \%$ of non-survivors of COVID-19 matched the grade of over DIC (35), indicating the deaths appear to be related to DIC (61). Anisodamine is well known for its dramatic therapeutic effect on DIC, in which the mechanisms are involved in the anti-platelet-aggregating, microcirculation-facilitating, thromboxane-B2-inhibiting, malondialdehyde-inhibiting, and 6-keto-PGF1 alpha-sparing effects (62). 3) Anisodamine and acute respiratory distress syndrome (ARDS): ARDS is a main lethal cause of severe COVID-19 patients (63). Anisodamine has been widely used to treat clinical and experimental ARDS in China since 1980s, and showed manifest therapeutic effect $(64,65)$. In 2003, anisodamine had also been used to treat patients of severe acute respiratory syndrome (SARS) with hypoxemia, and significantly decreased the mortality of SARS patients (66). 4) Anisodamine and organs protection: Anisodamine had displayed wide protection in other important organs, which were also affected in the COVID-19 infection. For example, anisodamine had cardioprotective effect through the suppression of cardiomyocytes apoptosis (67), protected against ischemic stroke via the $\alpha 7 \mathrm{nAChR}$ (68), ameliorated renal dysfunction by reducing oxidative stress, the inflammatory response and cell death (69). The $\alpha 7 \mathrm{nAChR}$ is widely distributed in these organs. Whether all these protective effects are related to the $\alpha 7 \mathrm{nAChR}$ and CAP, and the effect of anisodamine in multi-organs damaged by COVID-19, should be further explored.

As a muscarinic antagonist, the adverse effects of anisodamine include reducing salivation, lacrimation and sweat, diminishing gastrointestinal motility, mydriasis, and increasing heart rate, which is tolerable and will disappear within $1-3 \mathrm{~h}(70)$. The usual treatment dose in humans is 10 $\mathrm{mg} / \mathrm{kg}$, yet doses as high as $500 \mathrm{mg} / \mathrm{kg} /$ day did not produce any serious adverse effects (71).

\section{Herb Medicine}

Many herbs have proven effective in the treatment of inflammatory diseases. With the development of modern medicine, their action mechanisms have been gradually determined. Especially, accumulating evidence showed that CAP plays a critical role in the anti-inflammation effect of some herbs, which provides the theoretical basis of modern medicine for their usage in COVID-19 infection.

1) Huang-Lian-Jie-Du decoction (HLJDD) is a Chinese formulation, and composed of rhizoma coptidis, radix scutellariae, cortex phellodendri, and fructus gardenia (72). It has been used for the treatment of sepsis over 1,700 years (73). In fighting against COVID-19, it is widely accounted as an effective medicine in China. Recent studies showed that HLJDD could affect the levels of ACh and choline, suggesting its antiinflammatory effects possibly through its regulation in CAP (74). 2) Berberine is well known for its anti-inflammatory activity (75). It is an isoquinoline alkaloid extracted from rhizoma coptidis, and recently identified as an acetylcholinesterase inhibitor (76). It could inhibit acetyl cholinesterase enzyme (AChE) activity, increase $\mathrm{ACh}$ level and $\alpha 7 \mathrm{nAChR}$ expression, therefore modulate CAP, inhibit inflammatory responses, and finally improve cognitive function and insulin resistance $(77,78)$. 3) Andrograph is frequently used to treat respiratory inflammatory diseases (79). 3-dehydroandrographolide (3-DA) is a natural andrographolide product from andrographis herba. Studies showed that 3 -DA could bind with $\alpha 7 \mathrm{nAchR}$ and protect against LPS-induced acute lung injury in mice. Methyllycaconitine, a $\alpha 7 \mathrm{nAChR}$ specific inhibitor, could abolish this protective role (80). 4) Jiao-Tai-Wan (JTW), composed of coptis chinensis and cinnamon, is a famous prescription recorded in Han Shi Yi Tong, has been used for centuries for the treatment of insomnia (81). Recent studies found it could decrease the activity of acetylcholinesterase (AChE), increase the activity of choline acetyltransferase (ChAT), elevate the content of ACh, therefore activating cholinergic pathway and improving cognitive function (82). Its role in inflammation and COVID-19 infection is worthy of being explored. 5) Daikenchuto (DKT) is a gastrointestinal prokinetic Japanese herbal medicine (83). It contains four medical herbs: zanthoxylum fruit, processed dried ginger, ginseng, and malt sugar. Mari Endo et al. found that DKT could ameliorate inflammation in postoperative ileus by promoting $\mathrm{ACh}$ release from the cholinergic nerves, and this effect was partially suppressed in $\alpha 7 \mathrm{nAChR}$ knockout mice (84).

Qing-Fei-Pai-Du decoction (QFPDD) was the most widely used prescription in China's campaign to contain COVID-19 (85). Clinical observations suggested that QFPDD could significantly improve the abnormal laboratory indexes and clinical symptoms of COVID-19 patients, reduce the adverse reactions, and improve the therapeutic effect (86). QFPDD consists of 21 herbs including Ephedrae Herba, Glycyrrhizae 
Radix et Rhizoma Praeprata cum Melle, Armeniacae Semen Amarum, Gypsum Fibrosum, Cinnamomi Ramulus, Alismatis Rhizoma, Polyporus, Atractylodis Macrocephalae Rhizoma, Poria, Bupleuri Radix, Scutellariae Radix, Pinelliae Rhizoma Praepratum cum Zingibere et Alumine, Zingiberis Rhizoma Recens, Asteris Radix et Rhizoma, Farfarae Flos, Belamcandae Rhizoma, Asari Radix et Rhizoma, Dioscoreae Rhizoma, Aurantii Fructus Immaturus, Citri Reticulatae Pericarpium, and Pogostemonis Herba (87). Some compounds identified in QFPDD have been reported to act on targets of cholinergic synapse pathway. For example, earlier studies suggested that ephedrine could inhibit cholinesterases AChE (88), regulate acetylcholine receptor $\mathrm{nAChR}$ (89) and choline transporter CHT (90). These results suggest that QFPDD may regulate CAP to exhibit anti-inflammatory effects.

\section{Physical Activation}

\section{Vagus Nerve Stimulation (VNS)}

VNS may act as a physical approach to treat COVID-19 infection by activating intrinsic CAP $(26,91,92)$. In fact, VNS has been widely demonstrated to be a potentially anti-inflammatory therapy in experimental inflammatory disorder models such as sepsis, inflammatory bowel diseases, postoperative ileus and rheumatoid arthritis (93-96).

VNS is already approved by FDA for the treatment of drugresistant epilepsy and depression. The first device for VNS is invasive, which needs an electrode surgically implanted in the neck around the left vagus nerve (Figure 2A). Generally, highfrequency $(20-30 \mathrm{~Hz})$ stimulation is used to treat epilepsy and depression, whereas low-frequency $(1-10 \mathrm{~Hz})$ stimulation is used to activate the CAP in animal models (97). ClinicalTrials.gov, a service of the US National Institutes of Health (100), has received total 148 registrations of clinical studies on VNS. These studies are conducted in patients with epilepsy, depression, stroke, pain, diabetes, heart failure, and also inflammatory diseases, i.e. rheumatoid arthritis and inflammatory bowel diseases, demonstrating the interest for such a procedure in various health domains.

Such invasive VNS involves an additional intervention with surgical exposure of the vagus nerve. Most of the cases will encounter no problems. Perioperative complications of VNS are mostly related with cardiac dysrhythmias, which could be adjusted by elongating the off period (101). For severe COVID19 patients, careful evaluation and monitoring in cardiovascular system are still necessary. The most frequently acute complications of VNS implantation include temporary excessive salivation, mild coughs, paralysis of the vocal cord, lower facial weakness, the coercive feeling of coughing, rarely bradycardia, and very rarely, asystole, all of which are reversible (102). The infection at the implantation site is a rare complication (103).

Non-invasive VNS devices (nVNS) has become the latest hot spot in recent years and are widely used for sick individuals with relative safety and tolerability, such as GammaCore and NEMOS (104). GammaCore (electroCore LLC, Basking Ridge, NJ, USA) is a handheld, self-contained nVNS device approved by FDA, which directly contacts cervical skin surfaces and delivers electrical signal to the vagus (Figure 2B). This device was under investigation for headache, epilepsy and gastrointestinal disorders (105). Recently, it was clinically used to treat respiratory symptoms associated with COVID-19 in two patients, and showed a clinical benefit (98). In August 2020, the GammaCore Sapphire CV (nVNS) received an Emergency Use Authorization (EUA) from the FDA to treat patients with known or suspected COVID-19 associated asthma and respiratory distress with decreased blood oxygen (106).

NEMOS (Cerbomed, Erlangen, Germany) is an external device that provides transcutaneous VNS (tVNS) by using a dedicated intra-auricular electrode (like an earphone) which stimulates the auricular branch of the vagus nerve (Figure 2C) (99). Studies showed that auricular VNS could suppress LPSinduced inflammatory responses via $\alpha 7 \mathrm{nAChR}$-mediated CAP (107), indicating an intimate connection between auricular concha and efferent vagus nerve. Hence, it is also worthy of being tried in COVID-19 patients.

\section{Acupuncture}

Acupuncture, an important part of traditional Chinese medicine (TCM), has been used in China for the treatment of a variety of conditions for at least 5,200 years. It is nowadays widely used throughout the world including Asia, Europe, and the USA. Acupuncture is one of the most popular complementary and alternative therapies, and has steadily claimed its usefulness
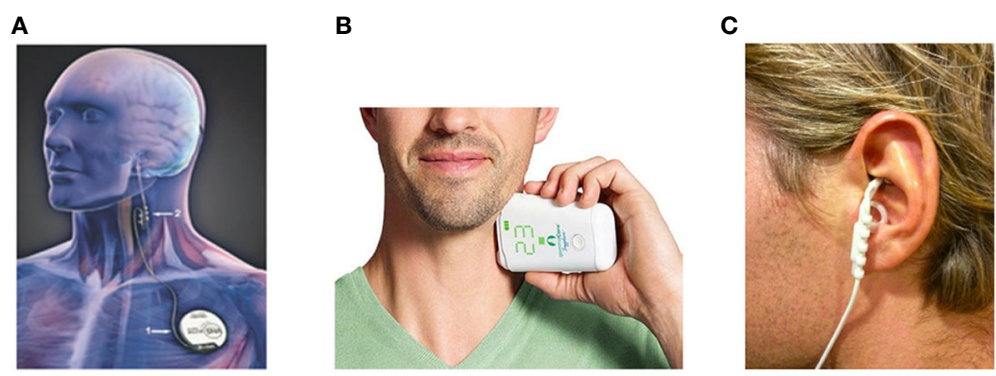

FIGURE 2 | The device of vagus nerve stimulation. (A) The first device for vagus nerve stimulation (VNS), a pulse generator is placed in a subcutaneous pocket in the left chest wall and a spiral electrode wrapped around the left vagus nerve in the neck (97). (B) GammaCore, a handheld, self-contained non-invasive VNS (nVNS) device, directly contacts cervical skin surfaces and delivers electrical signal to the vagus (98). (C) NEMOS, an external device that provides transcutaneous VNS (tVNS) by using a dedicated intra-auricular electrode, stimulates the auricular branch of the vagus nerve (99). 
(108). Therapeutic effects of acupuncture in inflammatory diseases have also been widely reported, with manual operation or electro-stimulation at varying acupuncture points (109).

The foundation of acupuncture is based on a complex meridians theory according to TCM. Modern physiologists have raised a "neural hypothesis" that acupuncture could primarily stimulate sensory nerves close to the inserting needle underneath the skin, transmit signals to brain, and produce clinical influence. This is the most rational basis for defining meridians (110). Some acupuncture points (such as ST36, PC6, and GV20) have been demonstrated to increase the vagal activity in experimental animals and human subjects (111-113). Furthermore, its systemic anti-inflammatory action has been highly proposed to be mediated by the CAP (114). Experimental data showed that acupuncture at Zusanli (ST36) and Feishu (BL13) points could reduce lung inflammation and improve lung function in COPD (chronic obstructive pulmonary disease) rats (115), at the acupoint "Baihui (GV20)" could attenuate cerebral inflammation and ischemic injury in MCAO (middle cerebral artery occlusion) rats (116). When $\alpha 7 \mathrm{nAchR}$ was blocked, these effects were revered.

Auricular branch of vagus nerve is a special vagal branch that innervates the body surface (117). Considering transcutaneous auricular VNS is effective in inflammation suppression via the CAP (107), the application of auricular acupuncture by pressing pills (cowherb seed) on ear acupoint, which is widely used in practice, is also recommended for the COVID-19 infection.

\section{CONCLUSION}

Accumulating evidence showed that the high level of cytokines indicates a poor prognosis in COVID-19, although there are some controversy supported by a few clinical studies (118). Here, we propose a potential therapeutic strategy to fight against cytokine storm in COVID-19 infection, namely activating organism's intrinsic CAP. We also provide a systemic approach (Graphical

\section{REFERENCES}

1. Lu R, Zhao X, Li J, Niu P, Yang B, Wu H, et al. Genomic characterisation and epidemiology of 2019 novel coronavirus: implications for virus origins and receptor binding. Lancet (2020) 395(10224):565-74. doi: 10.1016/ s0140-6736(20)30251-8

2. Li H, Liu L, Zhang D, Xu J, Dai H, Tang N, et al. SARS-CoV-2 and viral sepsis: observations and hypotheses. Lancet (2020) 395(10235):1517-20. doi: 10.1016/S0140-6736(20)30920-X

3. https://covid19.who.int/.

4. Zhou Y, Chi J, Lv W, Wang Y. Obesity and diabetes as high-risk factors for severe coronavirus disease 2019 (Covid-19). Diabetes Metab Res Rev (2020) e3377. doi: 10.1002/dmrr.3377

5. Kwenandar F, Japar KV, Damay V, Hariyanto TI, Tanaka M, Lugito NPH, et al. Coronavirus disease 2019 and cardiovascular system: A narrative review. Int J Cardiol Heart Vasc (2020) 29:100557. doi: 10.1016/ j.ijcha.2020.100557

6. Chen N, Zhou M, Dong X, Qu J, Gong F, Han Y, et al. Epidemiological and clinical characteristics of 99 cases of 2019 novel coronavirus pneumonia in Wuhan, China: a descriptive study. Lancet (2020) 395(10223):507-13. doi: 10.1016/S0140-6736(20)30211-7 abstract) including pharmacological activation (from modern medicine to herb medicine) and physical stimulation (from VNS to acupuncture), which are all feasible treatments against COVID-19 infection at this moment. Clinical studies are worthy of being carried out to investigate the efficacy and safety of the therapy in human subjects. Many of the pre-approved drugs and methods might be particularly valuable for use under emergency and for patients in developing and under-developed countries.

\section{DATA AVAILABILITY STATEMENT}

The original contributions presented in the study are included in the article/supplementary material. Further inquiries can be directed to the corresponding authors.

\section{AUTHOR CONTRIBUTIONS}

ZQ and KX collected the literature and drafted the paper. XL put forward the hypothesis and revised the manuscript. YS and D-FS participated in discussions. All the authors had final responsibility for the decision to publish. All authors contributed to the article and approved the submitted version.

\section{FUNDING}

This work was supported by National Science and Technology Major Project, National Natural Science Foundation of China (2018ZX09711002-003-015, 81773726 to XL, and 82003981 to ZQ), National Key Research and Development Program of China (2020YFC0845400, 2017YFC1700200 to Weidong Zhang), Shanghai Sailing Program (19YF1459500 to ZQ) and Science and Technology Innovation Action Plan Project (19401900100 to XL and 19431901400 to ZQ).

7. https://www.fda.gov/news-events/press-announcements/fda-approves-firsttreatment-covid-19.

8. https://www.who.int/news-room/feature-stories/detail/who-recommendsagainst-the-use-of-remdesivir-in-covid-19-patients.

9. https://www.cdc.gov/coronavirus/2019-ncov/hcp/vaccination.html.

10. Moore JB, June CH. Cytokine release syndrome in severe COVID-19. Science (2020) 368(6490):473-4. doi: 10.1126/science.abb8925

11. Wan Y, Shang J, Graham R, Baric RS, Li F. Receptor Recognition by the Novel Coronavirus from Wuhan: an Analysis Based on Decade-Long Structural Studies of SARS Coronavirus. J Virol (2020) 94(7):e00127-20. doi: 10.1128/JVI.00127-20

12. Iwasaki M, Saito J, Zhao H, Sakamoto A, Hirota K, Ma D. Inflammation Triggered by SARS-CoV-2 and ACE2 Augment Drives Multiple Organ Failure of Severe COVID-19: Molecular Mechanisms and Implications. Inflammation (2021) 44(1):13-34. doi: 10.1007/s10753-020-01337-3

13. Soy M, Keser G, Atagündüz P, Tabak F, Atagündüz I, Kayhan S. Cytokine storm in COVID-19: pathogenesis and overview of anti-inflammatory agents used in treatment. Clin Rheumatol (2020) 39(7):2085-94. doi: 10.1007/s10067-020-05190-5

14. Bahrami M, Kamalinejad M, Latifi SA, Seif F, Dadmehr M. Cytokine storm in COVID-19 and parthenolide: Preclinical evidence. Phytother Res (2020) 34(10):2429-30. doi: 10.1002/ptr.6776 
15. Russell CD, Millar JE, Baillie JK. Clinical evidence does not support corticosteroid treatment for 2019-nCoV lung injury. Lancet (2020) 395 (10223):473-5. doi: 10.1016/S0140-6736(20)30317-2

16. Figueiredo N, Chora A, Raquel H, Pejanovic N, Pereira P, Hartleben B, et al. Anthracyclines induce DNA damage response-mediated protection against severe sepsis. Immunity (2013) 39(5):874-84. doi: 10.1016/j.immuni. 2013.08.039

17. Russell B, Moss C, Rigg A, Van Hemelrijck M. COVID-19 and treatment with NSAIDs and corticosteroids: should we be limiting their use in the clinical setting? Ecancermedicalscience (2020) 14:1023. doi: 10.3332/ ecancer.2020.1023

18. Capuano A, Scavone C, Racagni G, Scaglione F. Italian Society of P. NSAIDs in patients with viral infections, including Covid-19: Victims or perpetrators? Pharmacol Res (2020) 157:104849. doi: 10.1016/j.phrs.2020.104849

19. Micallef J, Soeiro T, Jonville-Béra AP. Non-steroidal anti-inflammatory drugs, pharmacology, and COVID-19 infection. Therapie (2020) 75 (4):355-62. doi: 10.1016/j.therap.2020.05.003

20. Torjesen I. Covid-19: NICE advises against using NSAIDs for fever in patients with suspected cases. BMJ (2020) 369:m1409. doi: 10.1136/ bmj.m1409

21. Gerlach H. Agents to reduce cytokine storm. F1000Res (2016) 5:2909. doi: 10.12688/f1000research.9092.1

22. Stone JH, Frigault MJ, Serling-Boyd NJ, Fernandes AD, Harvey L, Foulkes AS, et al. Efficacy of Tocilizumab in Patients Hospitalized with Covid-19. N Engl J Med (2020) 383(24):2333-44. doi: 10.1056/NEJMoa2028836

23. Feldmann M, Maini RN, Woody JN, Holgate ST, Winter G, Rowland M, et al. Trials of anti-tumour necrosis factor therapy for COVID-19 are urgently needed. Lancet (2020) 395(10234):1407-9. doi: 10.1016/s01406736(20)30858-8

24. Zhang D, Guo R, Lei L, Liu H, Wang Y, Wang Y, et al. Use of siltuximab in patients with COVID-19 pneumonia requiring ventilatory support. medRxiv (2020). doi: 10.1101/2020.04.01.20048561

25. Turnquist C, Ryan BM, Horikawa I, Harris BT, Harris CC. Cytokine Storms in Cancer and COVID-19. Cancer Cell (2020) 38(5):598-601. doi: 10.1016/ j.ccell.2020.09.019

26. Borovikova LV, Ivanova S, Zhang M, Yang H, Botchkina GI, Watkins LR, et al. Vagus nerve stimulation attenuates the systemic inflammatory response to endotoxin. Nature (2000) 405(6785):458-62. doi: 10.1038/ 35013070

27. Wang H, Yu M, Ochani M, Amella CA, Tanovic M, Susarla S, et al. Nicotinic acetylcholine receptor alpha7 subunit is an essential regulator of inflammation. Nature (2003) 421(6921):384-8. doi: 10.1038/nature01339

28. Olofsson PS, Rosas-Ballina M, Levine YA, Tracey KJ. Rethinking inflammation: neural circuits in the regulation of immunity. Immunol Rev (2012) 248(1):188-204. doi: 10.1111/j.1600-065X.2012.01138.x

29. Inoue T, Okusa MD. Neuroimmune Control of Acute Kidney Injury and Inflammation. Nephron (2015) 131(2):97-101. doi: 10.1159/000438496

30. Olofsson PS, Katz DA, Rosas-Ballina M, Levine YA, Ochani M, ValdésFerrer SI, et al. $\alpha 7$ nicotinic acetylcholine receptor $(\alpha 7 \mathrm{nAChR})$ expression in bone marrow-derived non-T cells is required for the inflammatory reflex. Mol Med (2012) 18(1):539-43. doi: 10.2119/molmed.2011.00405

31. Broide RS, Leslie FM. The alpha7 nicotinic acetylcholine receptor in neuronal plasticity. Mol Neurobiol (1999) 20(1):1-16. doi: 10.1007/BF02741361

32. Lips KS, König P, Schätzle K, Pfeil U, Krasteva G, Spies M, et al. Coexpression and spatial association of nicotinic acetylcholine receptor subunits alpha7 and alpha10 in rat sympathetic neurons. J Mol Neurosci (2006) 30(1-2):15-6. doi: 10.1385/JMN:30:1:15

33. Kume T, Takada-Takatori Y. "Nicotinic Acetylcholine Receptor Signaling: Roles in Neuroprotection. 2018 Apr 4". In: A Akaike, S Shimohama, Y Misu, editors. Nicotinic Acetylcholine Receptor Signaling in Neuroprotection. Singapore: Springer (2018). Chapter 4

34. Pavlov VA, Chavan SS, Tracey KJ. Molecular and Functional Neuroscience in Immunity. Annu Rev Immunol (2018) 36:783-812. doi: 10.1146/annurevimmunol-042617-053158

35. de Jonge WJ, van der Zanden EP, The FO, Bijlsma MF, van Westerloo DJ, Bennink RJ, et al. Stimulation of the vagus nerve attenuates macrophage activation by activating the Jak2-STAT3 signaling pathway. Nat Immunol (2005) 6(8):844-51. doi: 10.1038/ni1229
36. Guarini S, Altavilla D, Cainazzo MM, Giuliani D, Bigiani A, Marini H, et al. Efferent vagal fibre stimulation blunts nuclear factor-kappaB activation and protects against hypovolemic hemorrhagic shock. Circulation (2003) 107 (8):1189-94. doi: 10.1161/01.cir.0000050627.90734.ed

37. Lu B, Kwan K, Levine YA, Olofsson PS, Yang H, Li J, et al. $\alpha 7$ nicotinic acetylcholine receptor signaling inhibits inflammasome activation by preventing mitochondrial DNA release. Mol Med (2014) 20(1):350-8. doi: 10.2119/molmed.2013.00117

38. Yamada M, Ichinose M. The cholinergic anti-inflammatory pathway: an innovative treatment strategy for respiratory diseases and their comorbidities. Curr Opin Pharmacol (2018) 40:18-25. doi: 10.1016/j.coph. 2017.12.003

39. Qin Z, Wan JJ, Sun Y, Wu T, Wang PY, Du P, et al. Nicotine protects against DSS colitis through regulating microRNA-124 and STAT3. J Mol Med (Berl) (2017) 95(2):221-33. doi: 10.1007/s00109-016-1473-5

40. Sun Y, Li Q, Gui H, Xu DP, Yang YL, Su DF, et al. MicroRNA-124 mediates the cholinergic anti-inflammatory action through inhibiting the production of pro-inflammatory cytokines. Cell Res (2013) 23(11):1270-83. doi: $10.1038 / \mathrm{cr} .2013 .116$

41. Qin Z, Wang PY, Wan JJ, Zhang Y, Wei J, Sun Y, et al. MicroRNA124-IL6R Mediates the Effect of Nicotine in Inflammatory Bowel Disease by Shifting Th1/Th2 Balance Toward Th1. Front Immunol (2020) 11:235. doi: 10.3389/ fimmu.2020.00235

42. Ingram JR, Thomas GA, Rhodes J, Green JT, Hawkes ND, Swift JL, et al. A randomized trial of nicotine enemas for active ulcerative colitis. Clin Gastroenterol Hepatol (2005) 3(11):1107-14. doi: 10.1016/s1542-3565(05) 00849-9

43. Ingram JR, Routledge P, Rhodes J, Marshall RW, Buss DC, Evans BK, et al. Nicotine enemas for treatment of ulcerative colitis: a study of the pharmacokinetics and adverse events associated with three doses of nicotine. Aliment Pharmacol Ther (2004) 20(8):859-65. doi: 10.1111/ j.1365-2036.2004.02199.x

44. Lunney PC, Leong RW. Review article: Ulcerative colitis, smoking and nicotine therapy. Aliment Pharmacol Ther (2012) 36(11-12):997-1008. doi: 10.1111/apt.12086

45. Pullan RD, Rhodes J, Ganesh S, Mani V, Morris JS, Williams GT, et al. Transdermal nicotine for active ulcerative colitis. N Engl J Med (1994) 330 (12):811-5. doi: 10.1056/nejm199403243301202

46. Guan W-J, Ni Z-Y, Hu Y, Liang W-H, Ou C-Q, He J-X, et al. Clinical characteristics of 2019 novel coronavirus infection in China. medRxiv (2020). doi: 10.1101/2020.02.06.20020974

47. Lippi G, Henry BM. Active smoking is not associated with severity of coronavirus disease 2019 (COVID-19). Eur J Intern Med (2020) 75:107-8. doi: $10.1016 /$ j.ejim.2020.03.014

48. Cai H. Sex difference and smoking predisposition in patients with COVID19. Lancet Respir Med (2020) 8(4):e20. doi: 10.1016/s2213-2600(20)30117-x

49. https://www.foxnews.com/health/coronavirus-patients-nicotine-patchesfrench-studyhttps://www.foxnews.com/health/coronavirus-patientsnicotine-patches-french-study.

50. Budisavljevic MN, Ploth DW. Nicotine and the kidney: Mr. Hyde, and perhaps some Dr. Jekyll. Am J Physiol Renal Physiol (2012) 302(9):F1082-3. doi: 10.1152/ajprenal.00067.2012

51. Sadis C, Teske G, Stokman G, Kubjak C, Claessen N, Moore F, et al. Nicotine protects kidney from renal ischemia/reperfusion injury through the cholinergic anti-inflammatory pathway. PLoS One (2007) 2(5):e469. doi: 10.1371 /journal.pone. 0000469

52. Benowitz NL. Nicotine addiction. N Engl J Med (2010) 362(24):2295-303. doi: 10.1056/NEJMra0809890

53. Anisodamine in treatment of some diseases with manifestations of acute microcirculatory insufficiency. Chin Med J (Engl) (1975) 1(2):127-32.

54. Xiu R-J. Studies on microcirculation in Institute of Basic Medical Sciences, Chinese Academy of Medical Sciences. Microvasc Res (1980) 20(3):371-3. doi: 10.1016/0026-2862(80)90065-5

55. Ruan QR, Zhang WJ, Hufnagl P, Kaun C, Binder BR, Wojta J. Anisodamine counteracts lipopolysaccharide-induced tissue factor and plasminogen activator inhibitor-1 expression in human endothelial cells: contribution of the NF-kappa b pathway. J Vasc Res (2001) 38(1):13-9. doi: 10.1159/ 000051025 
56. Li Q, Lei H, Liu A, Yang Y, Su D, Liu X. The antishock effect of anisodamine requires the upregulation of $\alpha 7$ nicotine acetylcholine receptors by IL-10. Life Sci (2011) 89(11-12):395-401. doi: 10.1016/j.lff.2011.07.008

57. Liu C, Shen FM, Le YY, Kong Y, Liu X, Cai GJ, et al. Antishock effect of anisodamine involves a novel pathway for activating alpha7 nicotinic acetylcholine receptor. Crit Care Med (2009) 37(2):634-41. doi: 10.1097/ CCM.0b013e31819598f5

58. van Westerloo DJ. A new approach to step on the vagal anti-inflammatory gas pedal. Crit Care Med (2009) 37(2):778-9. doi: 10.1097/ CCM.0b013e318194d004

59. Liu Q, Wang RS, Qu GQ, Wang YY, Liu P, Zhu YZ, et al. Gross examination report of a COVID-19 death autopsy. Fa Yi Xue Za Zhi (2020) 36(1):21-3. doi: 10.12116/j.issn.1004-5619.2020.01.005

60. Yang BF, Su DF. Antagonists of muscarinic receptors. In: Zhang CY, editor. Pharmacology, 7th Edn. Beijing: People's Medical Publishing House (2008). p. 72-9.

61. Tang N, Li D, Wang X, Sun Z. Abnormal coagulation parameters are associated with poor prognosis in patients with novel coronavirus pneumonia. J Thromb Haemost (2020) 18(4):844-7. doi: 10.1111/jth.14768

62. Zhang S, Chang AM, Li CF, Li ZJ, Yin ZJ, Zhao X, et al. Mechanism of the therapeutic effect of anisodamine in disseminated intravascular coagulation: study of platelet adhesion and aggregation, malondialdehyde, thromboxane B2, 6-keto-prostaglandin F1 alpha, and microcirculation. Exp Hematol (1987) 15(1):65-71.

63. Wu C, Chen X, Cai Y, Xia J, Zhou X, Xu S, et al. Risk Factors Associated With Acute Respiratory Distress Syndrome and Death in Patients With Coronavirus Disease 2019 Pneumonia in Wuhan, China. JAMA Intern Med (2020) 180(7):934-43. doi: 10.1001/jamainternmed.2020.0994

64. Jing YL, Wang YL, Sun Y, Zhao CX, Li HJ, Kong XY. [Experimental research of prevention and therapy effect of anisodamine on acute respiratory distress syndrome (ARDS)]. Zhongguo Ying Yong Sheng Li Xue Za Zhi (2009) 25 (4):557-60.

65. Liu YM. A study on changes of adrenergic receptors and their clinical significance in the lung of rats with respiratory distress syndrome. Zhonghua Jie He He Hu Xi Za Zhi (1993) 16(1):11-4, 61.

66. Yang GD. Patients of severe acute respiratory syndrome with hypoxemia treated by anisodamine. Zhongguo Wei Zhong Bing Ji Jiu Yi Xue (2003) 15 (8):452.

67. Xing K, Fu X, Jiang L, Wang Y, Li W, Gu X, et al. Cardioprotective Effect of Anisodamine Against Myocardial Ischemia Injury and its Influence on Cardiomyocytes Apoptosis. Cell Biochem Biophys (2015) 73(3):707-16. doi: 10.1007/s12013-015-0642-4

68. Qian J, Zhang JM, Lin LL, Dong WZ, Cheng YQ, Su DF, et al. A combination of neostigmine and anisodamine protects against ischemic stroke by activating $\alpha 7 n A C h R$. Int J Stroke (2015) 10(5):737-44. doi: 10.1111/ijs.12458

69. Li YF, Xu BY, An R, Du XF, Yu K, Sun JH, et al. Protective effect of anisodamine in rats with glycerol-induced acute kidney injury. BMC Nephrol (2019) 20(1):223. doi: 10.1186/s12882-019-1394-y

70. Poupko JM, Baskin SI, Moore E. The pharmacological properties of anisodamine. J Appl Toxicol (2007) 27(2):116-21. doi: 10.1002/jat.1154

71. Li QB, Pan R, Wang GF, Tang SX. Anisodamine as an effective drug to treat snakebites. J Nat Toxins (1999) 8(3):327-30.

72. Qi Y, Zhang Q, Zhu H. Huang-Lian Jie-Du decoction: a review on phytochemical, pharmacological and pharmacokinetic investigations. Chin Med (2019) 14:57. doi: 10.1186/s13020-019-0277-2

73. Wei Y, Shan L, Qiao L, Liu R, Hu Z, Zhang W. Protective Effects of HuangLian-Jie-Du-Tang against Polymicrobial Sepsis Induced by Cecal Ligation and Puncture in Rats. Evid Based Complement Alternat Med (2013) 2013:909624. doi: 10.1155/2013/909624

74. Xu D, Lv Y, Wang J, Yang M, Kong L. Deciphering the mechanism of Huang-Lian-Jie-Du-Decoction on the treatment of sepsis by formula decomposition and metabolomics: Enhancement of cholinergic pathways and inhibition of HMGB-1/TLR4/NF- KB signaling. Pharmacol Res (2017) 121:94-113. doi: 10.1016/j.phrs.2017.04.016

75. Zou K, Li Z, Zhang Y, Zhang HY, Li B, Zhu WL, et al. Advances in the study of berberine and its derivatives: a focus on anti-inflammatory and antitumor effects in the digestive system. Acta Pharmacol Sin (2017) 38(2):15767. doi: 10.1038/aps.2016.125
76. Cho KM, Yoo ID, Kim WG. 8-hydroxydihydrochelerythrine and 8hydroxydihydrosanguinarine with a potent acetylcholinesterase inhibitory activity from Chelidonium majus L. Biol Pharm Bull (2006) 29(11):2317-20. doi: 10.1248/bpb.29.2317

77. Wang K, Chen Q, Wu N, Li Y, Zhang R, Wang J, et al. Berberine Ameliorates Spatial Learning Memory Impairment and Modulates Cholinergic AntiInflammatory Pathway in Diabetic Rats. Front Pharmacol (2019) 10:1003. doi: 10.3389/fphar.2019.01003

78. Li F, Zhao YB, Wang DK, Zou X, Fang K, Wang KF. Berberine relieves insulin resistance via the cholinergic anti-inflammatory pathway in HepG2 cells. J Huazhong Univ Sci Technolog Med Sci (2016) 36(1):64-9. doi: 10.1007/s11596-016-1543-5

79. Yang N, Liu YY, Pan CS, Sun K, Wei XH, Mao XW, et al. Pretreatment with andrographolide pills $\left({ }^{\circledR}\right)$ attenuates lipopolysaccharide-induced pulmonary microcirculatory disturbance and acute lung injury in rats. Microcirculation (2014) 21(8):703-16. doi: 10.1111/micc.12152

80. Lu Z, Xie P, Zhang D, Sun P, Yang H, Ye J, et al. 3-Dehydroandrographolide protects against lipopolysaccharide-induced inflammation through the cholinergic anti-inflammatory pathway. Biochem Pharmacol (2018) 158:305-17. doi: 10.1016/j.bcp.2018.10.034

81. Quan SJ, He SM, Qian LL. Etudy on Mechanish of Jiao Tai Wan on Treatment of Insomnia by Communication between Heart and Kidney. J Liaoning Univ Trad Chin Med (2011) 13:12-4.

82. Wang XC, Xu YM, Li HY, Wu CY, Xu TT, Luo NC, et al. Jiao-Tai-Wan Improves Cognitive Dysfunctions through Cholinergic Pathway in Scopolamine-Treated Mice. BioMed Res Int (2018) 2018:3538763. doi: $10.1155 / 2018 / 3538763$

83. Manabe N, Camilleri M, Rao A, Wong BS, Burton D, Busciglio I, et al. Effect of daikenchuto (TU-100) on gastrointestinal and colonic transit in humans. Am J Physiol Gastrointest Liver Physiol (2010) 298(6):G970-5. doi: 10.1152/ ajpgi.00043.2010

84. Endo M, Hori M, Ozaki H, Oikawa T, Hanawa T. Daikenchuto, a traditional Japanese herbal medicine, ameliorates postoperative ileus by anti-inflammatory action through nicotinic acetylcholine receptors. J Gastroenterol (2014) 49 (6):1026-39. doi: 10.1007/s00535-013-0854-6

85. Ren JL, Zhang AH, Wang XJ. Traditional Chinese medicine for COVID-19 treatment. Pharmacol Res (2020) 155:104743. doi: 10.1016/j.phrs.2020. 104743

86. Li KY, An W, Xia F, Chen M, Yang P, Liao YL, et al. Observation on clinical effect of modified Qingfeipaidu decoction in treatment of COVID-19. Chin Trad Herb Drugs (2020) (01):13-8.

87. National Health Commission of the People's Republic of China. Guideline on diagnosis and treatment of COVID-19 (Trial 6th edition). Available at: http://www.nhc.gov.cn/xcs/zhengcwj/202002/8334a8326dd94d329df351 d7da8aefc2.shtml (Accessed Feb 23, 2020). in Chinese.

88. Maizel EB, Rozengart EV, Khakimov Iu P, Abduvakhabov AA, Aslanov Kh A. [Ephedrine, salsoline and cytisine derivatives as substrates and inhibitirs of cholinesterases]. Biokhimiia (1978) 43(7):1150-6.

89. Kinali M, Beeson D, Pitt MC, Jungbluth H, Simonds AK, Aloysius A, et al. Congenital myasthenic syndromes in childhood: diagnostic and management challenges. J Neuroimmunol (2008) 201-202:6-12. doi: 10.1016/j.jneuroim.2008.06.026

90. Fischer W, Metzner L, Hoffmann K, Neubert RH, Brandsch M. Substrate specificity and mechanism of the intestinal clonidine uptake by Caco- 2 cells. Pharm Res (2006) 23(1):131-7. doi: 10.1007/s11095-005-8925-x

91. Kaniusas E, Szeles JC, Kampusch S, Alfageme-Lopez N, Yucuma-Conde D, Li X, et al. Non-invasive Auricular Vagus Nerve Stimulation as a Potential Treatment for Covid19-Originated Acute Respiratory Distress Syndrome. Front Physiol (2020) 11:890. doi: 10.3389/fphys.2020.00890

92. Bonaz B, Sinniger V, Pellissier S. Targeting the cholinergic antiinflammatory pathway with vagus nerve stimulation in patients with Covid-19? Bioelectron Med (2020) 6:15. doi: 10.1186/s42234-020-00051-7

93. Kessler W, Diedrich S, Menges P, Ebker T, Nielson M, Partecke LI, et al. The role of the vagus nerve: modulation of the inflammatory reaction in murine polymicrobial sepsis. Mediators Inflammation (2012) 2012:467620. doi: $10.1155 / 2012 / 467620$

94. Koopman FA, Chavan SS, Miljko S, Grazio S, Sokolovic S, Schuurman PR, et al. Vagus nerve stimulation inhibits cytokine production and attenuates 
disease severity in rheumatoid arthritis. Proc Natl Acad Sci USA (2016) 113 (29):8284-9. doi: 10.1073/pnas.1605635113

95. Stakenborg N, Wolthuis AM, Gomez-Pinilla PJ, Farro G, Di Giovangiulio M, Bosmans $\mathrm{G}$, et al. Abdominal vagus nerve stimulation as a new therapeutic approach to prevent postoperative ileus. Neurogastroenterol Motil (2017) 29: e13075. doi: 10.1111/nmo.13075

96. Sinniger V, Pellissier S, Fauvelle F, Trocmé C, Hoffmann D, Vercueil L, et al. A 12-month pilot study outcomes of vagus nerve stimulation in Crohn's disease. Neurogastroenterol Motil (2020) 32(10):e13911. doi: 10.1111/ nmo. 13911

97. Bonaz B, Picq C, Sinniger V, Mayol JF, Clarençon D. Vagus nerve stimulation: from epilepsy to the cholinergic anti-inflammatory pathway. Neurogastroenterol Motil (2013) 25(3):208-21.

98. Staats P, Giannakopoulos G, Blake J, Liebler E, Levy RM. The Use of Noninvasive Vagus Nerve Stimulation to Treat Respiratory Symptoms Associated With COVID-19: A Theoretical Hypothesis and Early Clinical Experience. Neuromodulation (2020) 23(6):784-8. doi: 10.1111/ner.13172

99. Van Leusden JW, Sellaro R, Colzato LS. Transcutaneous Vagal Nerve Stimulation (tVNS): a new neuromodulation tool in healthy humans? Front Psychol (2015) 6:102. doi: 10.3389/fpsyg.2015.00102

100. https://clinicaltrials.gov/.

101. Ekmekçi H, Kaptan H. Vagus Nerve Stimulation. Open Access Maced J Med Sci (2017) 5(3):391-4. doi: 10.3889/oamjms.2017.056

102. Amar AP, Levy ML, Apuzzoc MLJ. Vagus nerve stimulation for intractable epilepsy. In: Rengechary S, editor. Neurosurgical Operative Atlas. Chicago, IL: American Association of Neurological Surgeons (2000) 9:179-88.

103. Lim SN, Lee ST, Tsai YT, Chen IA, Tu PH, Chen JL, et al. Electrical stimulation of the anterior nucleus of the thalamus for intractable epilepsy: a long-term follow-up study. Epilepsia (2007) 48(2):342-7. doi: 10.1111/ j.1528-1167.2006.00898.x

104. Diener HC, Goadsby PJ, Ashina M, Al-Karagholi MA, Sinclair A, Mitsikostas $\mathrm{D}$, et al. Non-invasive vagus nerve stimulation (nVNS) for the preventive treatment of episodic migraine: The multicentre, double-blind, randomised, sham-controlled PREMIUM trial. Cephalalgia (2019) 39(12):1475-87. doi: $10.1177 / 0333102419876920$

105. Ben-Menachem E, Revesz D, Simon BJ, Silberstein S. Surgically implanted and non-invasive vagus nerve stimulation: a review of efficacy, safety and tolerability. Eur J Neurol (2015) 22(9):1260-8. doi: 10.1111/ene.12629

106. https://www.gammacore.com/covid-19/.

107. Zhao YX, He W, Jing XH, Liu JL, Rong PJ, Ben H, et al. Transcutaneous auricular vagus nerve stimulation protects endotoxemic rat from lipopolysaccharide-induced inflammation. Evid Based Complement Alternat Med (2012) 2012:627023. doi: 10.1155/2012/627023

108. Shan WS, Chi Ho CV. Acupuncture: filling the effectiveness gaps in Western medicine? Br J Gen Pract (2011) 61(587):374-5. doi: 10.3399/bjgp11X572607
109. Zijlstra FJ, van den Berg-de Lange I, Huygen FJ, Klein J. Anti-inflammatory actions of acupuncture. Mediators Inflammation (2003) 12(2):59-69. doi: $10.1080 / 0962935031000114943$

110. Longhurst JC. Defining meridians: a modern basis of understanding. J Acupunct Meridian Stud (2010) 3(2):67-74. doi: 10.1016/s2005-2901(10) 60014-3

111. Huang ST, Chen GY, Lo HM, Lin JG, Lee YS, Kuo CD. Increase in the vagal modulation by acupuncture at neiguan point in the healthy subjects. Am J Chin Med (2005) 33(1):157-64. doi: 10.1142/s0192415x0500276x

112. Li Z, Jiao K, Chen M, Wang C. Effect of magnitopuncture on sympathetic and parasympathetic nerve activities in healthy drivers-assessment by power spectrum analysis of heart rate variability. Eur J Appl Physiol (2003) 88(45):404-10. doi: 10.1007/s00421-002-0747-5

113. Hsu CC, Weng CS, Liu TS, Tsai YS, Chang YH. Effects of electrical acupuncture on acupoint BL15 evaluated in terms of heart rate variability, pulse rate variability and skin conductance response. Am J Chin Med (2006) 34(1):23-36. doi: 10.1142/s0192415x06003606

114. Kavoussi B, Ross BE. The neuroimmune basis of anti-inflammatory acupuncture. Integr Cancer Ther (2007) 6(3):251-7. doi: 10.1177/1534735407305892

115. Zhang XF, Xiang SY, Geng WY, Cong WJ, Lu J, Jiang CW, et al. Electroacupuncture regulates the cholinergic anti-inflammatory pathway in a rat model of chronic obstructive pulmonary disease. J Integr Med (2018) 16 (6):418-26. doi: 10.1016/j.joim.2018.10.003

116. Wang Q, Wang F, Li X, Yang Q, Li X, Xu N, et al. Electroacupuncture pretreatment attenuates cerebral ischemic injury through $\alpha 7$ nicotinic acetylcholine receptor-mediated inhibition of high-mobility group box 1 release in rats. J Neuroinflamm (2012) 9(1):24. doi: 10.1186/1742-2094-9-24

117. He W, Rong PJ, Li L, Ben H, Zhu B, Litscher G. Auricular Acupuncture May Suppress Epileptic Seizures via Activating the Parasympathetic Nervous System: A Hypothesis Based on Innovative Methods. Evid Based Complement Alternat Med (2012) 2012:615476. doi: 10.1155/2012/615476

118. Gao Y, Wang C, Kang K, Peng Y, Luo Y, Liu H, et al. Cytokine Storm May Not Be the Chief Culprit for the Deterioration of COVID-19. Viral Immunol (2020). doi: 10.1089/vim.2020.0243

Conflict of Interest: The authors declare that the research was conducted in the absence of any commercial or financial relationships that could be construed as a potential conflict of interest.

Copyright (c) 2021 Qin, Xiang, Su, Sun and Liu. This is an open-access article distributed under the terms of the Creative Commons Attribution License (CC BY). The use, distribution or reproduction in other forums is permitted, provided the original author(s) and the copyright owner(s) are credited and that the original publication in this journal is cited, in accordance with accepted academic practice. No use, distribution or reproduction is permitted which does not comply with these terms. 